\title{
MICROSATELLITE GENETIC VARIATION IN CULTURED POPULATIONS OF AFRICAN CATFISH (Clarias gariepinus) IN INDONESIA
}

\author{
Imron\#, Dadan Sunandar, and Evi Tahapari \\ Research Institute for Freshwater Fish Breeding and Aquaculture \\ (Received 6 December 2010 ; Accepted 16 March 2011 )
}

\begin{abstract}
African catfish, Clarias gariepinus, is one of economically important farmed species in Indonesia. To support the development of aquaculture industry, high genetic quality of both broodstock and seeds is required and breeding program is considered as viable option. Information on genetic variation of the populations being considered to form a base population may give insight toward the appropriate strategy to be implemented in breeding program. This study was aimed to assess genetic variation in farmed populations of catfish in Indonesia using microsatellite markers with special emphasis on their use to develop breeding program. Three populations of farmed catfish, namely Dumbo, Paiton, and Sangkuriang were collected. Fifteen individuals representing each population were screened for microsatellite variability using seven primer sets (cga01, cga02, cga03, cga05, cga06, cga09, cga10). Results found that with exception of two loci (cga01 and $\mathrm{cg} 02$ ) which had a slight increase, the other four loci showed reduction in the number of alleles ranging from $35 \%$ to $80 \%$ depending on loci. Farmed populations also showed heterozygote deficient and inbreeding level, being the highest was found in Sangkuriang and the least was observed in Dumbo population. Individuals within populations contributed most (95\%) while interpopulation variation accounted for only $5 \%$ of the total genetic variation. Populations of Dumbo and Sangkuriang were genetically similar while populations of Paiton were genetically different from both Dumbo and Sangkuriang. Viewed from genetic perspective, by combining all information emerging from this study, the best possible strategy to establish a base population with broad genetic base and less inbreeding would be to combine all the populations into a synthetic base population.
\end{abstract}

KEYWORDS: microsatellite variability, farmed population, Clarias gariepinus

\section{INTRODUCTION}

Catfish farming of the genus Clarias, specifically African catfish, Clarias gariepinus has been one of important aquaculture industries in Indonesia. In 2006, total production of this species reached 77,332 tons and putting Indonesia as the second biggest African catfish producing country in the world (FAO, 2009). The role that catfish faming industry plays in the future is expected to be increasingly important along with the target set by government to place Indonesia as the biggest fish or fishery product producing country in the world. Improved genetic quality of both fish broodstock and seeds is considered as impor-

\# Corresponding author. Research Institute for Freshwater Fish Breeding and Aquaculture, Jl. Raya 2 Sukamandi, Subang 41256, West Java, Indonesia. Tel.: +62 260520500

E-mail address: imronnawawi@gmail.com; imronnawawi@yahoo.com 
tant components to support the achievement of the target. Genetic improvement through selective breeding program is a method frequently used and has proven capable of increasing aquaculture productivity such as the case with salmon (Gjedrem, 2005) and tilapia.

A successful selective breeding program, indicated by significant and continuous genetic gain from generation to generation, normally started with a base population that has a high level of genetic variation. Base population for breeding program of salmon for instance, was made up of about 40 fragmented natural populations found within the rivers across Norway (Gjedrem, 2005), while 8 populations of both wild and cultured tilapia populations comprised the base population for breeding program of genetically improved farmed tilapia (GIFT) (Circa et al., 1995). Simulation study found that a minimum of 4 populations are required to form base population which ensure substantial and continued genetic gain (Holtsmark et al., 2006).

Method for assessing genetic variation in quantitative trait in breeding program has conventionally been conducted by measuring the variation in phenotypic traits of interest. While this approach is acknowledged to be the best (Reed \& Frankham, 2001) and is widely practised, it requires the existence of an on going breeding program from which measurement on quantitative traits can be conducted. In a situation where a breeding program has not been started, this approach obviously could not be applied and alternative approaches by using variety of molecular markers are usually applied as a proxy to give insight on the variation in phenotypic traits.

Among a number of molecular genetic markers, microsatellite is considered to be one of the most powerful markers. Its high levels of polymorphisms, codominant nature, and highly repeatable make them ideal markers for a range of applications. With respect to aquaculture applications, it has been successfully applied in studies of genetic variation (Carlsson et al., 2006; Lundrigan et al., 2005), population structure, parentage analyses (Borrell et al., 2004; Ji et al., 2005; Selvamani et al., 2001), stock discrimination (de Leon et al., 1998; Hsu et al., 2010), estimation of quantitative genetic parameter (Lucas et al., 2006), effective population size and inbreeding level (Bierne et al., 1998; Koljonen et al., 2002), as well as for detection of quantitative trait loci (Sakamoto,
2004) and marker assisted selection (Xu et al., 2003).

In order to establish a breeding program which has potentials to give substantial and long term genetic gain through selective breeding, a base population with a broad genetic base from which a selection program would be base on, is a prerequisite. This study was aimed to assess genetic variation within and among the African catfish stocks in Indonesia using microsatellite DNA markers. Specifically, it was aimed to address such questions as 1) structure and amount of genetic variation within and among Indonesian catfish populations, 2) genetic differences of farmed populations relative to the wild type counterpart, and 3) how the best strategy to make use the presently available catfish germplasm to develop a successful breeding program.

\section{MATERIALS AND METHOD}

\section{Sample Collection}

Three stocks of African catfish currently widely used in Indonesian catfish farming were collected. They were Dumbo, Sangkuriang, and Paiton stocks. Both the Dumbo and Paiton stocks are presumably of the same species which is Clarias gariepinus. The Sangkuriang stock is descendant of the Dumbo which was established through intergeneration backcross mating. A more detail description on the origin and the history of their introduction has been described elsewhere (Imron et al., 2010). Fifteen individuals from each stock were sampled. Non-destructive sampling was carried out by cutting approximately $5 \mathrm{~cm}$ end part of the snout barb of each individual sampled. Immediately after incision the individual tissue sample was then put in individual tubes filled with $80 \%$ ethanol and let them in room temperature until analysis.

\section{Laboratory Analysis}

\section{DNA Extraction}

Genomic DNA of each individual sample was extracted using animal DNA extraction kit following the protocols recommended by manufacturer (Dneasy miniprep column, Qiagen) with slight modification. Briefly, the protocol consists of series of steps including tissue lysis, DNA precipitation, binding DNA to the column, washing and elution. Tissue lysis 
was performed by weighing of approximately $25 \mathrm{mg}$ of tissue sample and chopping it with a surgical blade into small pieces. Alternatively, the tissue could also be prepared by grinding it using pastel and mortar or other homogenizing systems. The tissue was lysed by adding $180 \mu \mathrm{L}$ of lysis buffer, $20 \mu \mathrm{L}$ of proteinase $\mathrm{K}$, followed by incubation in $56^{\circ} \mathrm{C}$ for $1-3$ hours. The DNA in the lysate was then precipitated by adding $200 \mu \mathrm{L}$ buffer and $200 \mu \mathrm{L}$ of $96 \%$ $100 \%$ ethanol. Binding DNA to the column was carried out by spinning the mixture (lysate, buffer, and ethanol) at 8,000 rpm for $1 \mathrm{~min}$. The column binding DNA was then washed twice by adding $500 \mu \mathrm{L}$ of washing buffer followed by spinning at 14,000 for 3 min. Finally, the DNA bound to the column was then eluted by adding $200 \mu \mathrm{L}$ elution buffer, letting it for 1 min in room temperature and terminated by spinning it at 8,000 rpm for $1 \mathrm{~min}$.

To check the success of genomic DNA extraction process, the sample was run on horizontal gel electrophoresis. The sample was loaded onto the $1.5 \%$ agarose gel, powered with 70 volt electricity and run for 30 minutes. The gel was then viewed using gel documentation system (UVP). Successful genomic DNA extrac- tion process would be characterized by an intact single band with high molecular weight. Individual sample showing a good DNA extract was then proceeded to the next step which was amplification of polymorphic microsatellite alleles.

\section{PCR Amplification}

Amplification of polymorphic microsatellite loci was performed using thermal cycling system (mycycler, Biorad). Seven microsatellite primers (Galbusera et al., 1996) which previously have been used and were able to amplify polymorphic alleles were used (Table 1). For each primer set, a fluorescence dye either FAM (blue), HEX (blue), or TET (green) was added to the 5 -end of forward primer (Table 1).

PCR reaction was carried out in $0.2 \mathrm{~mL}$ thin wall PCR tube. To maintain consistency in PCR condition from one running to another, preoptimized PCR mastermix specified for microsatellite amplification (Type It microsatellite, Qiagen) was used instead of the customized one. The master mix contains preoptimized composition of Taq, buffer, dNTP

Table 1. List of microsatellite primers and recommended annealing temperature (Galbusera et al., 1996) used to amplify polymorphic microsatellite alleles in cultured populations of Clarias gariepinus

\begin{tabular}{|c|c|c|c|c|}
\hline Primer & GB & Sequence ( $\left.5^{\prime}-3^{\prime}\right)$ & $\begin{array}{c}\text { Fluorescence } \\
\text { label }\end{array}$ & $\begin{array}{l}\mathrm{TM} \\
\left({ }^{\circ} \mathrm{C}\right)\end{array}$ \\
\hline Cga01 & U30862 & $\begin{array}{l}\text { F: GGCTAAAAGAACCCTGTCTG } \\
\text { R: TACAGCGTCGATAAGCCAGG }\end{array}$ & FAM & 59 \\
\hline Cga02 & U30863 & $\begin{array}{l}\text { F: GCTAGTGTGAACGCAAGGC } \\
\text { R: ACCTCTGAGATAAAACACAGC }\end{array}$ & HEX & 58 \\
\hline Cga03 & U30864 & $\begin{array}{l}\text { F: CACTTCTTACATTTGTGCCC } \\
\text { R: АACСТGTATTGATTTCTTCCC }\end{array}$ & FAM & 56 \\
\hline Cga05 & U30866 & $\begin{array}{l}\text { F: TCCACATTAAGGACAACCACCG } \\
\text { R: TTTCCAGTTCACGACTGCCG }\end{array}$ & FAM & 60 \\
\hline Cga06 & U30867 & $\begin{array}{l}\text { F: CAGCTCGTGTTTAATTTGGC } \\
\text { R: TTGTACGAGAACCGTCCCAGG }\end{array}$ & HEX & 60 \\
\hline Cga09 & U30871 & $\begin{array}{l}\text { F: CGTCCACTTCCCCTAGAGCG } \\
\text { R: CAGCTGCATTACCATACATGG }\end{array}$ & FAM & 65 \\
\hline Cgalo & U30870 & $\begin{array}{l}\text { F: GCTGTAGCAAAAATGCAGATGC } \\
\text { R: TCTCCAGAGATCTAGGCTGTCC }\end{array}$ & TET & 60 \\
\hline
\end{tabular}

Note: $\mathrm{GB}=$ Gene Bank Accession Number, $\mathrm{TM}=$ Annealing temperature 
and $\mathrm{MgCl}_{2}$. One $\mu \mathrm{L}$ of genomic DNA template was added into the mixture of $6.5 \mu \mathrm{L}$ of preoptimized master mix and $1 \mu \mathrm{L}$ of $10 \mathrm{pmol}$ of each primer. Only single pair of primer was used in every PCR reaction, no multiplexing in $P C R$ reaction was applied. Three $\mu \mathrm{L}$ of nuclease free water was added to make total volume of each reaction of $12.5 \mu \mathrm{L}$. Thermal profile for amplification consisted of $4 \mathrm{~min}$. at $94^{\circ} \mathrm{C}$ for initial denaturation, followed by 30 cycles of amplification consisting of $45 \mathrm{sec}$. at $95^{\circ} \mathrm{C}$ for denaturation, $30 \mathrm{sec}$. at recommended temperature as shown in Table 1 for annealing, and $30 \mathrm{sec}$. at $72^{\circ} \mathrm{C}$ for extension. Final extension was at $72^{\circ} \mathrm{C}$ for $10 \mathrm{~min}$.

\section{Genotyping and Allele Scoring}

The PCR product was then sent to external sequencing service for genotyping. Genotyping for PCR products amplified by $\mathrm{Cga03}$ primer set were run in singleplex, in which only single PCR product was genotyped in every single reaction. The other six PCR products were genotyped in multiplexing manner, in which two PCR products labelled with different colour of florescence dyes were mixed in one reaction. The combinations of amplified microsatellite markers run simultaneously were cga01 and cga02, cga05 and cga 10, and cga06 and cga09. The resulting data in the form of both banding patterns and electropherogram were edited and analysed for allele scoring using Genemarker system. The allelic scores were then used for estimation of relevant genetic parameters.

\section{Data Analyses}

A number of intra and interpopulation genetic variability parameters, including number of detected allele (A), observed (O) and expected heterozygosities (HE), HardyWeinberg equilibrium (HW) and fixation index within population $\left(\mathrm{F}_{15}\right)$ were computed using statistical genetic software Fstat version 2.9.3. (Goudet, 2001). Number of identified allele among populations may vary depending on sample size. To eliminate bias in the number of allele per population due to sample size, a parameter called allelic richness (RS) (El Mousadik \& Petit, 1996) was added. This estimate was obtained from implementing Genepop (Raymond \& Rousset, 1995) Partitioning total genetic variation into within and among populations was carried by performing analysis of molecular variance (AMOVA) using Arlequin software (Schneider et al., 2000), followed by pairwise comparisons. To get insight on the differences of genetic variation in these cultured population from the wild population counterpart, a comparison was carried out using data obtained by Galbusera et al. (1996) who worked with natural populations of Clarias gariepinus originating from Kenya as a reference.

\section{RESULT}

The seven microsatellite primer sets used in this study successfully amplified polymorphic microsatellite loci. However one primer sets (Cga06) resulted in amplifying PCR products with unbalanced number in particular population. Inclusion of this marker for further analyses may result in reduction in sample size which potentially bias many inferences due to small sample size. For this reason, the Cga06 locus was excluded and further analyses were base on the variability profile of six microsatellite loci. Summary statistics of several parameters including sample size per population, number of identified alleles, observed and expected heterozygosity, and Hardy-Weinberg equilibrium are presented in Table 2. Genetic structure of populations which was partitioned into intra- and interpopulations is presented in Table 3, while genetic divergence among populations as revealed by pairwaise $F_{S T}$ is presented in Table 4. Comparison of genetic variation, particularly in the number of identified allele (allelic richness) between farmed and wild populations is presented in Figure 1.

\section{Microsatellite Genetic Diversity}

Overall observed heterozygosity within population range from 0.43 in Sangkuriang to 0.602 in Paiton. There were both inter locus and inter population variations with respect to the amount of the observed and expected heterozygosity. Several loci experienced heterozygote excess suggesting the frequency of heterozygous is higher than that expected under equilibrium. However this excess did not differ significantly from equilibrium as indicated by non significant level of HW P-values. Other loci showed indication of heterozygote deficit, meaning that frequency of heterozygous genotypes was lower than that expected under equilibrium. For several population-loci combinations, this deficit was statistically significant (Table 2). The phenomenon of heterozygote deficit was also supported by 
parameter of within population fixation index $\left(\mathrm{F}_{1 \mathrm{~S}}\right)$. Fixation index within population as expressed in $F_{\text {IS }}$ (Table 2 ) may reflect, to some extent, breeding status of population. Positive sign of $\mathrm{F}_{\mathrm{IS}}$ indicates inbreeding while negative $F_{\text {IS }}$ indicates outbreeding. Table 2 shows that all populations showed positive sign of $F_{15}$ values indicating certain level of inbreeding.

Table 2. Summary statistics of genetic variation assessed by microsatellite markers in 3 populations of cultured catfish, Clarias gariepinus cultured in Indonesia Data for wild population were taken from the study of Galbusera et al. (1996). Bold printed figures indicate statistically significant P-value

\begin{tabular}{|c|c|c|c|c|c|}
\hline \multirow{2}{*}{\multicolumn{2}{|c|}{ Parameters }} & \multicolumn{4}{|c|}{ Population } \\
\hline & & Dumbo & Pait on & Sangkuriang & Wild \\
\hline \multirow[t]{7}{*}{ Cgal } & Allele range (base pairs) & $81-107$ & $81-111$ & $81-115$ & $92-104$ \\
\hline & Number of sample $(\mathrm{N})$ & 15 & 13 & 15 & \\
\hline & Number of allele (A) & 6 & 6 & 6 & 5 \\
\hline & Observed heterozygosity (HO) & 0.466 & 0.769 & 0.733 & \\
\hline & Expected heterozygosity (HE) & 0.853 & 0.742 & 0.814 & \\
\hline & Fixation index $\left(F_{\mid S}\right)$ & 0.425 & -0.053 & 0.086 & \\
\hline & P-value of Hardy-Weinberg (HW) & 0.015 & 0.131 & 0.460 & \\
\hline \multirow[t]{7}{*}{ Cga2 } & Allele range (base pairs) & $101-117$ & $99-117$ & $103-117$ & $102-110$ \\
\hline & Number of sample $(\mathrm{N})$ & 15 & 14 & 15 & \\
\hline & Number of allele (A) & 8 & 6 & 6 & 5 \\
\hline & Observed heterozygosity (HO) & 0.867 & 0.643 & 0.533 & \\
\hline & Expected heterozygosity (HE) & 0.823 & 0.817 & 0.647 & \\
\hline & Fixation index $\left(F_{1 S}\right)$ & -0.055 & 0.196 & 0.176 & \\
\hline & P-value of Hardy-Weinberg (HW) & 0.865 & 0.001 & 0.426 & \\
\hline \multirow[t]{7}{*}{ Cga3 } & Allele range (base pairs) & $147-157$ & $149-157$ & $147-157$ & $142-168$ \\
\hline & Number of sample $(\mathrm{N})$ & 15 & 15 & 15 & \\
\hline & Number of allele (A) & 3 & 2 & 3 & 13 \\
\hline & Observed heterozygosity (HO) & 0.133 & 0.533 & 0.200 & \\
\hline & Expected heterozygosity (HE) & 0.363 & 0.405 & 0.251 & \\
\hline & Fixation index $\left(F_{\mid S}\right)$ & 0.309 & -0.333 & -0.050 & \\
\hline & P-value of Hardy-Weinberg (HW) & 0.001 & 0.508 & 1,000 & \\
\hline \multirow[t]{7}{*}{ Cga5 } & Allele range (base pairs) & $195-201$ & $193-201$ & $193-201$ & $204-212$ \\
\hline & Number of sample $(\mathrm{N})$ & 15 & 15 & 15 & \\
\hline & Number of allele $(A)$ & 2 & 3 & 4 & 5 \\
\hline & Observed heterozygosity $(\mathrm{HO})$ & 0.267 & 0.333 & 0.333 & \\
\hline & Expected heterozygosity (HE) & 0.331 & 0.651 & 0.494 & \\
\hline & Fixation index $\left(F_{\mid S}\right)$ & 0.200 & 0.402 & 0.255 & \\
\hline & P-value of Hardy-Weinberg (HW) & 0.4605 & 0.028 & 0.300 & \\
\hline \multirow[t]{7}{*}{ Cga9 } & Allele range (base pairs) & $175-193$ & $175-193$ & $175-193$ & $183-196$ \\
\hline & Number of sample $(\mathrm{N})$ & 15 & 15 & 15 & \\
\hline & Number of allele (A) & 4 & 5 & 5 & 7 \\
\hline & Observed heterozygosity $(\mathrm{HO})$ & 0.733 & 0.533 & 0.600 & \\
\hline & Expected heterozygosity (HE) & 0.671 & 0.644 & 0.772 & \\
\hline & Fixation index $\left(F_{1 S}\right)$ & -0.096 & 0.122 & 0.182 & \\
\hline & P-value of Hardy-Weinberg (HW) & 0.504 & 0.231 & 0.446 & \\
\hline
\end{tabular}


Table 2. (Continued)

\begin{tabular}{|c|c|c|c|c|c|}
\hline \multirow{2}{*}{\multicolumn{2}{|c|}{ Parameters }} & \multicolumn{4}{|c|}{ Population } \\
\hline & & Dumbo & Pait on & Sangkuriang & Wild \\
\hline \multirow[t]{7}{*}{ Cgalo } & Allele range (base pairs) & 97-105 & $95-111$ & $97-105$ & $102-138$ \\
\hline & Number of sample $(\mathrm{N})$ & 15 & 15 & 15 & \\
\hline & Number of allele $(A)$ & 5 & 6 & 5 & 14 \\
\hline & Observed heterozygosity $(\mathrm{HO})$ & 0.933 & 0.600 & 0.400 & \\
\hline & Expected heterozygosity (HE) & 0.752 & 0.800 & 0.818 & \\
\hline & Fixation index $\left(\mathrm{F}_{\mathrm{IS}}\right)$ & -0.252 & 0.232 & 0.485 & \\
\hline & P-value of Hardy-Weinberg (HW) & 0.235 & 0.129 & 0.0002 & \\
\hline \multicolumn{2}{|c|}{ A mean (overall) } & 4.30 & 4.30 & 4.50 & 7 \\
\hline \multicolumn{2}{|c|}{ RS mean (overall) } & 4,686 & 4,438 & 4,522 & \\
\hline \multicolumn{2}{|c|}{$\mathrm{F}_{\mathrm{IS}}$ (overall) } & 0.049 & 0.120 & 0.222 & \\
\hline \multicolumn{2}{|c|}{ HO (overall) } & 0.57 & 0.60 & 0.433 & 0.61 \\
\hline
\end{tabular}

The highest inbreeding level was found in the population of Sangkuriang, followed by Paiton and Dumbo.

\section{Genetic Differentiation Among Populations}

Genetic variation comprised cultured populations of catfish in Indonesia mainly was contributed by intrapopulation variation. This component accounted for almost $95 \%$ of the total genetic variation in all populations (Table 3 ). Despite small proportion of genetic variation contributed by interpopulation differences, it does not mean that all populations were genetically homogenous. Pairwise analysis of interpopulation differences (Table 4) shows that there are significant differences in particular pairs of populations. The differences particularly occurred in pairwise comparisons between Paiton and Sangkuriang and between

Table 3. Partition of genetic variation into the components of among and within populations as shown by the Analysis of Molecular Variance (AMOVA)

\begin{tabular}{ccccc}
\hline $\begin{array}{c}\text { Source of } \\
\text { variation }\end{array}$ & $\begin{array}{c}\text { Degree of } \\
\text { freed om }\end{array}$ & $\begin{array}{c}\text { Sum of } \\
\text { squares }\end{array}$ & $\begin{array}{c}\text { Variance } \\
\text { component s }\end{array}$ & $\begin{array}{c}\text { Percentage of } \\
\text { variation }\end{array}$ \\
\hline Among populations & 2 & 10,489 & 0.11474 & 5.99 \\
Within populations & 87 & 156,800 & 180,230 & 94.01 \\
\hline Total & $\mathbf{8 9}$ & $\mathbf{1 6 7 , 2 8 9}$ & & \\
\hline
\end{tabular}

Fixation Index

FST: 0.05985

Table 4. Pairwise $\mathrm{F}_{\mathrm{ST}}$ (below diagonal) and its corresponding P-values (above diagonal) among populations of cultured catfish, Clarias gariepinus in Indonesia

\begin{tabular}{lccc}
\hline & Dumbo & Pait on & Sangkuriang \\
\hline Dumbo & - & $0.0000 \pm 0.0000$ & $0.6306 \pm 0.0525$ \\
Paiton & 0.08876 & - & $0.0000 \pm 0.0000$ \\
Sangkuriang & -0.00187 & 0.08703 & - \\
\hline
\end{tabular}


Paiton and Dumbo. No significant difference in pairwise comparison between Dumbo and sangkuriang was observed.

\section{Comparison With Natural Population}

Compared with natural population, all the cultured stocks investigated in this study have experienced reduction in the number of allele identified in $67 \%$ of the loci used (Figure 1). The declines ranged from $35 \%$ in locus cga05 to $80 \%$ in locus cga03. The rest of the loci show an increasing instead of decreasing allelic number. The magnitude of the increases, however, is less than those of decreases. A somewhat different profile was shown by average observed heterozygosity estimates. The Dumbo and Paiton showed relatively similar levels of observed average heterozygosity to each other and to the wild, while sangkuriang showed the least (Figure 1).

\section{DISCUSSION}

The farmed populations of African catfish analysed in this study were characterized in general by 1) lower level of genetic variation, particularly in allelic richness relative to the wild stock counterpart, 2) heterozygote deficit and inbreeding occurred in all populations with slightly different degree, 3) most genetic variation (95\%) was contributed by within population variation, and 4) lack of genetic diver- gence between Dumbo and Sangkuriang, while significant differences were obseved between both populations and Paiton. Reduced genetic variation (in term of allelic richness) in farmed animal population compared to the wild, have been a relatively common phenomenon. Several factors such as genetic drift, small number of founder and selective pressure, either separately or in combination, may result in the observed phenomena. A number of studies in other fish species such as Arctic charr, Salvelinus alpinus (Lundrigan et al., 2005), Kuruma prawn, Marsupenaeus japonicus (Luan et al., 2006), and Atlantic salmon, Salmo salar (Norris et al., 1999) have found similar trend. Considering the history of African catfish in Indonesia, it is likely that the combination of above mentioned factors have lead to the reduction in allelic richness found in the cultured catfish in Indonesia. Loss of genetic variation reflected in allelic richness is more obvious than that reflected in heterozygosity since the former is more sensitive than the latter (Spencer et al., 2000).

Heterozygosity deficit as expressed in significant differences from HW equilibrium, and inbreeding as expressed in positive sign of $\mathrm{F}_{\text {Is }}$ are correlated parameters. In most cases, these parameters are associated with founder effect, in which individuals within founding population were of limited number or were consanguineous (see e.g. Norris et al., 1999).

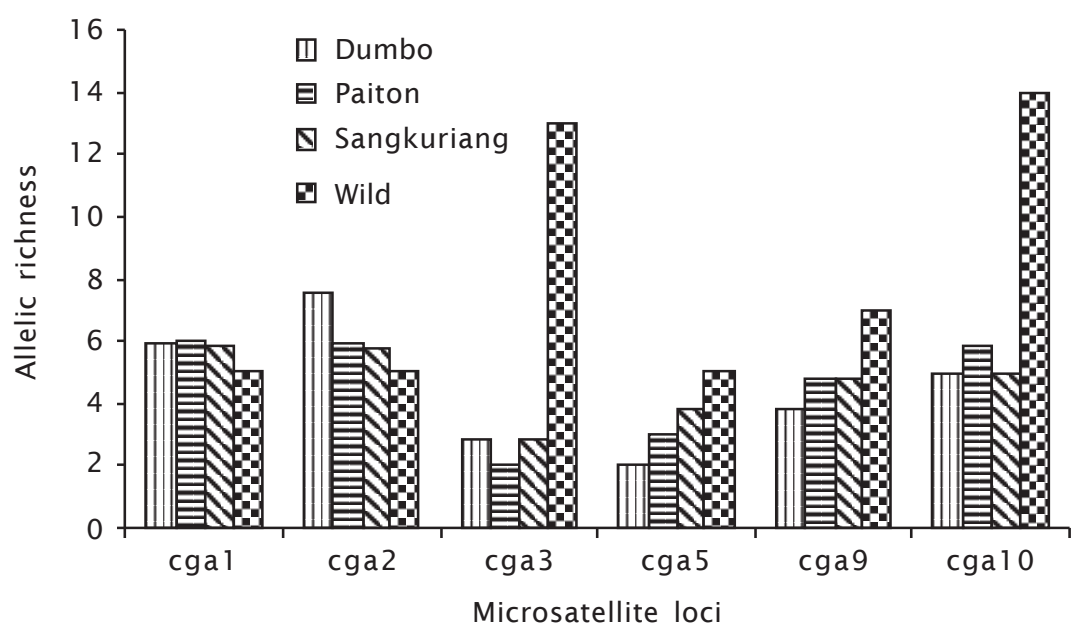

Figure 1. Comparison of allelic richness between cultured and wild populations of catfish based on six microsatellite loci. Allelic richness for the wild was inferred by the Author from Galbusera et al. (1996) based on the information given in the paper 
Similar explanation seems hold for the data emerged in this study. The higher levels of $F_{15}$ found in Sangkuriang and Paiton compared to that found in Dumbo suggest that limited number of broodstock or consanguineous individuals had been used in the deliberate breeding program of both populations, a situation that seemed to be true. Conversely, the absence of similar practice in Dumbo has prevented this population from accumulating high level of inbreeding.

\section{Population Differentiation}

Population genetic differentiation discovered in this study, in which Paiton population significantly differed from both Dumbo and Sangkuriang, while no such a pattern was observed between Dumbo and Sangkuriang, was in line with the history and origin of the populations. As previously mentioned in the Methods, and also has been described in Imron et al. (2010), populations of Dumbo and Sangkuriang were actually originated from the same populations. Specifically, Sangkuriang is descendant of Dumbo, is it was established from a backcross mating between the second and the sixth generations of the Dumbo. Hence, similarity in genetic make up of both populations is not surprising and is expected. Likewise, the differentiations between Population of Paiton from Dumbo and from Sangkuriang are also anticipated, due either to differences in gene pool or history of introduction. While no clear information with respect to the source of gene pool of both populations is available, the difference in their introduction year is well documented. The dumbo and Paiton were introduced in 1985 and 1999, respectively.

\section{Implications for Breeding Program}

The microsatellite genetic diversity parameters discovered in this study could be used in breeding program for genetic improvement of quantitative traits through at least two ways; estimation of genetic variation in quantitative traits and broodstock management particularly in relation to population's inbreeding coefficient. The use of microsatellite genetic diversity as an indicator for variation in quantitative traits is based on the premise that positive correlation exist in the amount and pattern of variation within quantitative traits and molecular microsatellite markers. Most studies accept the presence of correlation between variation in molecular genetic markers and those at phenotypic traits. However, there have been disagreements with respect to the degree of correlations. On one group, several studies suggest that the positive and strong correlation exist. Xu et al. (2003) for instance, found significant correlation between particular $\mathrm{M} 1$ microsatellite alleles and Taura Syndrome Virus (TSV)-susceptible and TSV-resistant lines in Pacific white shrimp, Litopenaeus vannamei. Similar findings, in which strong correlations exist between molecular and morphological were also provided by Merila \& Crnokrak, (2001), who performed meta-analysis on plant and animal taxa using both allozyme and microsatellite markers. On the other group, Reed \& Frankham, (2001) who did meta-analysis study on 71 data sets, mostly derived from allozyme markers, found a weak correlation between molecular and morphological variation. To see how strong the microsatellite diversity parameters discovered in this study is correlated with the performance in quantitative traits, experimental studies assessing their associations are required. The data in the present study show that genetic diversity as shown by allelic richness and heterozygosity measures of Paiton and Dumbo populations are comparable while the Sangkuriang shows the least. Assuming positive and strong correlation between microsatellite diversity parameters and quantitative traits is the case, the Sangkuriang populations would have the least variation in quantitative traits compared to both Dumbo and Paiton.

While exact relationships between genetic variability at molecular neutral marker and performance of particular phenotypic traits of interest have not been quite consistent and remain to be tested, most breeders agree on the negative impact of inbreeding level on the performance of economically important quantitative traits (inbreeding depression). Accordingly, the general strategy in breeding program, particularly selective breeding, is to keep inbreeding coefficient at a minimum level. As shown in the previous section, all farmed catfish populations investigated in this study showed certain levels of inbreeding, being the highest was found in Sangkuriang population and the least was found in Dumbo. Elimination or keeping population's inbreeding at minimum level could be conducted by mating of unrelated individuals. In practice, this can be done by crossing of individuals among different 
populations. Mating of individuals coming from different farmed populations could eliminate inbreeding but could not recover the alleles lost during domestication. Hence, if allelic richness is also desirable, then introduction of individuals from natural populations and inclusion those individuals into base population of breeding program could be carried out. This strategy has been successfully applied in selective breeding of GIFT tilapia (Eknath et al., 1993).

\section{CONCLUSION}

Inter-individual variation comprised most (95\%) of genetic variation in the farmed populations of African catfish in Indonesia, while interpopulation differences accounted for only $5 \%$ of total variation. The populations also have experienced reduction in genetic variation compared to the wild, being the most striking was observed in allelic richness (35\%-80\%). Although the decline in heterozygosity was less noticeable than that in allelic richness, all farmed population have experienced varying degree of heterozygote deficit leading to inbreeding. Considering all the information available, a base population for selective breeding program would possibly be best obtained by combining at least all the germ plasm of farmed catfish available into synthetic base population. Introduction and incorporation of new wild catfish populations into breeding program could also be recommended, particularly when recovery of alleles lost in farmed population is desirable.

\section{ACKNOWLEDGEMENTS}

This study was funded by research grant of Agency for Research and Development of Marine and Fisheries fiscal year 2010. Authors would like to express sincere thanks to the members of Breeding and Genetic laboratory of Research Institute for Freshwater Fish Breeding and Aquaculture (RIFFBA) for all the assistance given during the course of the study.

\section{REFERENCES}

Bierne, N., Launey, S., Naciri-Graven, Y., \& Bonhomme, F. 1998. Early Effect of Inbreeding as Revealed by Microsatellite Analyses on Ostrea edulis Larvae. Genetics, 148: 1,893-1,906.

Borrell, Y.J., Alvarez, J., Vazquez, E., Pato, C.F., Tapia, C.M., Sanchez, J.A., \& Blanco, G.
2004. Applying microsatellites to the management of farmed turbot stocks (Scophthalmus maximus L.) in hatcheries. Aquaculture, 241: 133-150.

Carlsson, J., Morrison, C.L., \& Reece, K.S. 2006. Wild and aquaculture populations of the eastern oyster compared using microsatellites. J. of Heredity, 97: 595-598.

Circa, A.V., Eknath, A.E., \& Taduan, A.G. 1995. Genetic improvement of farmed tilapias: the growth performance of the gift strain of Nile tilapia (Oreochromis niloticus) in rice-fish environments. Aquaculture, 137: 329-330.

de Leon, F.J.G., Canonne, M., Quillet, E., Bonhomme, F., \& Chatain, B. 1998. The application of microsatellite markers to breeding programmes in the sea bass, Dicentrarchus labrax. Aquaculture, 159: 303-316.

Eknath, A.E., Tayamen, M.M., Palada-de Vera, M.S., Danting, J.C., Reyes, R.A., Dionisio, E.E., Capili, J.B., Bolivar, H.L., Abella, T.A., \& Circa, A.V. 1993. Genetic improvement of farmed tilapias: the growth performance of eight strains of Oreochromis niloticus tested in different farm environments. Aquaculture, 111:171-188.

El Mousadik, A., \& Petit, R. 1996. High level of genetic differentiation for allelic richness among populations of the argan tree Argania spinosa (L.) Skeels endemic to Morocco. Theoretical and Applied Genetics, 92: 832-839.

FAO. 2009. FishStat: Universal software for fishery statistical time series v. 2.3. Data and Statistics Unit. FAO, Rome.

Galbusera, P., Volckaert, F.A., Hellemans, B., \& Ollevier, F. 1996. Isolation and characterization of microsatellite markers in the African catfish Clarias gariepinus (Burchell, 1822). Molecular Ecology, 5: 703-705.

Genetic and Biometry Laboratory, University of Geneva. 2000. Arlequin; A software for population genetic analysis data. Release 2.000. Genetic and Biometry Laboratory, University of Geneva, Switzerland.

Gjedrem, T. 2005. Selection and Breeding Programs in Aquaculture Springer, Dodrecht Heidelberg London New York, 364 pp.

Goudet, J. 2001. FSTAT, a program to estimate and test gene diversities and fixation indices (version 2.9.3). Available from http:/ /www.unil.ch/izea/softwares/fstat.htm!. 
Holtsmark, M., Sonesson, A.K., Gjerde, B., \& Klemetsdal, G. 2006. Number of contributing subpopulations and mating design in the base population when establishing a selective breeding program for fish. Aquaculture, 258: 241-249.

Hsu, T.H., Wang, Z.Y., Takata, K., Onozato, H., Hara, T., \& Gwo, J.C. 2010 . Use of microsatellite DNA and amplified fragment length polymorphism for Cherry salmon (Oncorhynchus masou) complex identification. Aquaculture Research, 41: e316e325.

Imron, Tahapari, E., Sari, R.D., \& Hudaidah, S. 2010. Growth and Survival of Catfish, Clarias Gariepinus, Having Different Domestication History in Indoor Nursery. Proceedings of International Conference of Aquaculture Indonesia, Hang Tuah University, October 2010 (in press).

Ji, Y.J., Hua, Y.P., Liu, Y.D., Liu, H.T., Shi, C.M., Li, D.M., \& Zhang, D.X. 2005. Ten polymorphic microsatellite markers developed in the masson pine moth Dendrolimus punctatus Walker (Lepidoptera: Lasiocampidae). Molecular Ecology Notes, 5: 911-913.

Koljonen, M.-L., Tahtinen, J., Saisa, M., \& Koskiniemi, J. 2002. Maintenance of genetic diversity of Atlantic salmon (Salmo salar) by captive breeding programmes and the geographic distribution of microsatellite variation. Aquaculture, 212: 69-92.

Luan, S., Kong, J., \& Wang, Q.Y. 2006. Genetic variation of wild and cultured populations of the Kuruma prawn Marsupenaeus japonicus (Bate 1888) using microsatellites. Aquaculture Research, 37: 785-792.

Lucas, T., Macbeth, M., Degnan, S.M., Knibb, W., \& Degnan, B.M. 2006. Heritability estimates for growth in the tropical abalone Haliotis asinina using microsatellites to assign parentage. Aquaculture In Press, Corrected Proof. Aquaculture, 259: 146-152.

Lundrigan, T.A., Reist, J.D., \& Ferguson, M.M. 2005. Microsatellite genetic variation within and among Arctic charr (Salvelinus alpinus) from aquaculture and natural populations in North America. Aquaculture, 244: 63-75.

Merila, J. \& Crnokrak, P. 2001. Comparison of genetic differentiation at marker loci and quantitative traits. J. of Evolutionary Biology, 14: 892- 903.

Norris, A.T., Bradley, D.G., \& Cunningham, E.P. 1999. Microsatellite genetic variation between and within farmed and wild Atlantic salmon (Salmo salar) populations. Aquaculture, 180: 247-264.

Raymond, M. \& Rousset, F. 1995. GENEPOP (version 1.2) population genetics software for exact test and ecumenism. J. of Heredity, 86: 248-249.

Reed, D.H. \& Frankham, R. 2001. How closely correlated are molecular and quantitative measures of genetic variation? a meta analysis. Evolution, 55: 1,095-1,103.

Sakamoto, T. 2004. Construction of genetic linkage maps and QTL analysis using microsatellite markers in fish. Nippon Suisan Gakkaishi (Japanese Edition) 70: 496-499.

Selvamani, M.J.P., Degnan, S.M., \& Degnan, B.M. 2001. Microsatellite genotyping of individual abalone larvae: Parentage assignment in aquaculture. Marine Biotechnology, 3: 478-485.

Spencer, C.C., Neigel, J.E., \& Leberg, P.L. 2000. Experimental evaluation of the usefulness of microsatellite DNA for detecting demographic bottlenecks. Molecular Ecology, 9: 1,517-1,528.

Xu, Z., Wyrzykowski, J., Alcivar-Warren, A., Moss, S.M., Argue, B.J., Arce, S.M., Traub, M., Calderon, F.R.O., Lotz, J., \& Breland, V. 2003. Genetic Analyses for TSV-Susceptible and TSV-Resistant Pacific White Shrimp Litopenaeus vannamei using M1 Microsatellite. J. of the World Aquaculture Society, 34: 332-343. 